\title{
Persistence with Biological Disease-modifying Antirheumatic Drugs and Its Associated Resource Utilization and Costs
}

\author{
Rosarin Sruamsiri ${ }^{1,2} \cdot$ Hideto Kameda $\cdot$ Jörg Mahlich ${ }^{1,4}$
}

Published online: 2 August 2018

(c) The Author(s) 2018

\begin{abstract}
Objective The study assessed persistence rates of biological disease-modifying antirheumatic drugs (bDMARDs) for the treatment of rheumatoid arthritis in Japan and compared resource utilization and treatment costs between persistence and non-persistence groups.

Methods Data were extracted from a Japanese claims database between 2009 and 2015. bDMARD-naïve patients were identified and included in the final analysis. Survival analysis was used to estimate 1-year persistence rates for current bDMARDs. Propensity score matching was applied to control for potential treatment selection bias. Resource utilization and healthcare costs were calculated 1 year before and after initiation of bDMARDs and compared between persistence and non-persistence groups.

Results A total of 6153 bDMARD-naïve patients were identified and the overall 1-year persistence rate was $85 \%$ (95\% CI 84-86). Overall, 1-year outpatient visits increased from 10 at baseline to 16 after bDMARD treatment, while the number of hospital admissions declined from 3.3 to 1.6. The non-persistence group had a larger increase in outpatient visits after bDMARD initiation compared with the persistence group (8-16 vs. 10-16, respectively) and a smaller decrease in hospital admissions (3.1-1.9 vs. 3.5-1.4, respectively). Persistence was associated with a reduction in total healthcare costs of US\$760.

Conclusions Japanese bDMARD-naïve patients with RA have a high persistence rate with those treatments. The reduction in medication costs in non-persistent patients is offset by higher hospitalization costs, making non-persistence more expensive.
\end{abstract}

Electronic supplementary material The online version of this article (https://doi.org/10.1007/s40801-018-0139-8) contains supplementary material, which is available to authorized users.

Jörg Mahlich

joerg.mahlich@gmail.com

1 Health Economics, Janssen Pharmaceutical KK, 5-2, Nishi-kanda 3-chome Chiyoda-ku, 101-0065 Tokyo, Japan

2 Center of Pharmaceutical Outcomes Research, Naresuan University, Muang Phitsanulok, Thailand

3 Division of Rheumatology, Toho University Ohashi Medical Center, Tokyo, Japan

4 Düsseldorf Institute for Competition Economics (DICE), University of Düsseldorf, Düsseldorf, Germany

\section{Key Points}

In general, drug survival of biological agents in Japanese patients with rheumatoid arthritis is high, indicating that relatively few patients discontinue their treatment.

Patients who discontinued their treatment or switched to another treatment caused higher costs to the healthcare system compared to patients who were persistent with their initial treatment.

\section{Introduction}

Rheumatoid arthritis (RA) is defined as a systemic autoimmune inflammatory disease characterized by chronic synovitis in multiple joints resulting in severe pain and deformity. The estimated prevalence of RA in Japan in 2011 was 1.24 million corresponding to $1.0 \%$ of the population [1]. 
Biological disease-modifying antirheumatic drugs (DMARDs) have improved the lives of many patients with RA and have been reported to delay and even halt the clinical progression of the disease [2]. Furthermore, biological DMARDs (bDMARDs) are not only effective in reducing symptoms [3], their use is also associated with a decrease in mortality [4].

Despite these documented benefits of bDMARDs in the treatment of RA, persistence rates, which refers to the duration of time from initiation to discontinuation of therapy [5], have been shown to vary considerably depending on the country, types of health centres as well as the specific drug being investigated. A systematic review of 52 studies reported 1-year persistence rates that ranged from 32.0 to $90.9 \%[6]$.

Few studies have evaluated persistence rates for bDMARDs in a Japanese population. One claims data analysis found that the overall 1-year persistence rate in Japan of $86 \%$ was higher than international rates. Of note, persistence rates for the bDMARD-naïve subpopulation were above $95 \%$. Persistence was also higher for older patients and lower for patients with a high co-morbidity score [7]. A prospective cohort study evaluated patients who were treated with the bDMARDs infliximab (IFX), etanercept (ETN) or tocilizumab (TCZ) [8]. Compared with ETN, patients who took infliximab and tocilizumab were significantly more likely to discontinue treatment because of adverse events. Lastly, results from a Japanese Rheumatic Diseases registry suggested 1-year drug continuation rates between $73 \%$ for infliximab and $89 \%$ for tocilizumab [9].

With one notable exception from Sweden, few studies have calculated the cost implications of low persistence rates [10]. In the Swedish study, the authors compared the cost for patients who reliably took their medication over a 1-year period with that of patients who discontinued their treatment. Although patients who were non-persistent had lower drug costs, the authors found that this reduction in medication costs was counterbalanced by higher hospitalization costs, making non-persistence more costly than persistence. Another study using a US managed-care administrative claims database found that patients with a treatment persistence of $>80 \%$ had higher mean total healthcare costs compared with those with a treatment persistence of $<80 \%$. This difference was largely due to higher pharmacy costs. However, non-pharmacy costs were lower in the persistence cohort [11]. Evidence also suggests that switching medications during treatment impacts healthcare costs. A US database study revealed that both first-line and second-line switchers had significantly higher monthly total healthcare costs after the switch than non-switchers (\$3759 vs. \$2343) and (\$3956 vs. \$2616), respectively [12].

While numerous factors have been found to impact persistence with bDMARDs and its impact on healthcare costs, these results are not transferrable across countries and cultures. Therefore, we aimed to identify persistence rates for bDMARDs in a Japanese population of bDMARD-naïve patients, using a similar approach to that employed in the Swedish study. In addition, to broaden the scope of our investigation, we also evaluated RA-related drug costs since previous studies did not evaluate drug costs.

\section{Methods}

\subsection{Data Source}

We utilized commercially available hospital claims data from Medical Data Vision Co., Ltd. (MDV) This is an administrative database for inpatients and outpatients that includes approximately 4,400,000 patients and represents around $3 \%$ of the total Japanese population. The age distribution in the database is $13.5 \% 0-14$ years old, $52.4 \%$ 15-64 years old, and 34.1\% 65 years and older, and resembles that of the general population [13]. The data were obtained from hospital electronic information systems derived from 147 acute-phase hospitals throughout Japan. The hospitals operate 40,000 beds and are registered as Diagnosis Procedure Combination (DPC) hospitals. The DPC is a Diagnosis-Related Group (DRG)-like flat fee system that was introduced in 2003 for big hospitals in Japan [14]. Costs that occur outside this hospital network are not captured. The database had been used in health economic or epidemiological analyses of many different indications such as schizophrenia [15], influenza [16], infectious diseases [17], RA [18, 19], cardiovascular disease [20], diabetes [21], and prostate cancer [22, 23]. The time span of our analysis was from March 2009 to September 2015.

\subsection{Study Population and Study Design}

The study population was identified based on the International Classification of Diseases, 10th revision (ICD-10). Patients with RA were diagnosed as ICD 10: M05, M06.0, M06.2-M06.9. bDMARD-naïve patients were defined as patients who had received no prescriptions for biological agents during the first 3 months of their observation period. The 3-month 'washout' period is common in database analysis [24] and we choose this time period to ensure comparability across results of different database studies. Patients were required to have at least two diagnoses of RA and to have received at least two prescriptions for treatment of RA (DMARDs including bDMARDs). The following conventional DMARDs were identified for treatment in Japan: sulfasalazine (SSZ), methotrexate (MTX), leflunomide (LEF), tacrolimus (TAC), penicillamine (PNC), actarit, lobenzarit, iguratimod, bucillamine and gold salts. 
Biological agents included infliximab (Remicade), etanercept (Enbrel), adalimumab (Humira), golimumab (Simponi), abatacept (Orencia), tocilizumab (Actemra), certolizumab pegol (Cimzia), tofacitinib (Xeljanz). The index date was defined as the first claim for a bDMARD medication. At least 24 months of follow-up data in the database were also required for all eligible patients to determine healthcare utilization and cost (12 months prior to bDMARD initiation and 12 months after bDMARD treatment). We excluded children and patients $<18$ years of age. In addition, because some bDMARDs are indicated in the treatment of certain diseases such as Crohn's disease, psoriasis, psoriatic arthritis, ankylosing spondylitis and juvenile idiopathic arthritis, we also excluded patients with the following diagnoses: Crohn's disease, ankylosing spondylitis, juvenile idiopathic arthritis, psoriasis, ulcerative colitis and/or Behçet's disease.

A total of six matched cohorts were created: golimumab (GOL) versus etanercept (ETN), GOL versus adalumumab (ADL), GOL versus infliximab (IFX), GOL versus certolizumab pegol (CTZ), GOL versus tocilizumab (TCZ) and GOL versus abatacept (ABT). GOL served as the anchor point in this analysis because a recent review concluded that GOL might be associated with higher persistence rates in a real-world setting [25].

\subsection{Outcomes}

\subsubsection{Persistence Rates}

We used survival analysis to estimate 6-, 12-, and 18-month persistence rates for the bDMARDs GOL, ETN,
IFX, TCZ, ADL, ABT and CTZ. The persistence rate was defined as the time from treatment initiation (index date) until discontinuation of the index bDMARDs (Fig. 1a). This definition of persistence was consistent with that employed in other claims data-based studies of RA [10, $26]$ and other indications [27, 28].

In addition, a sensitivity analysis was performed with alternative gap definitions of 30 and 90 days. We defined the index date as the first bDMARD prescription in the database. Patients were categorized as discontinuing the index bDMARD treatment if either of the following occurred first: (1) a gap in the days' supply of the index biological agent that exceeded the medication gap was encountered, or (2) the patient switched from the index bDMARD to other treatment(s) during the follow-up. In the base case, we used a medication gap of 60 days to define medication discontinuation. We also assessed the sensitivity of our results by using alternative gap definitions, namely 30 and 90 days.

To estimate the days' supply of index medication, we referred to the standard recommended dose for RA treatment [29] for each bDMARD multiplied by the number of bDMARDs per prescription. We use the recommended dose and not the maximum dose that can be used for heavy patients. The prescription period of individual prescriptions was derived by multiplying a standard defined daily dose (DDD) with the number of bDMARDs dispensed (Online Supplementary material, Appendix 1).
Fig. 1 Persistence measurement and healthcare utilization measurement (a) Persistence measurement

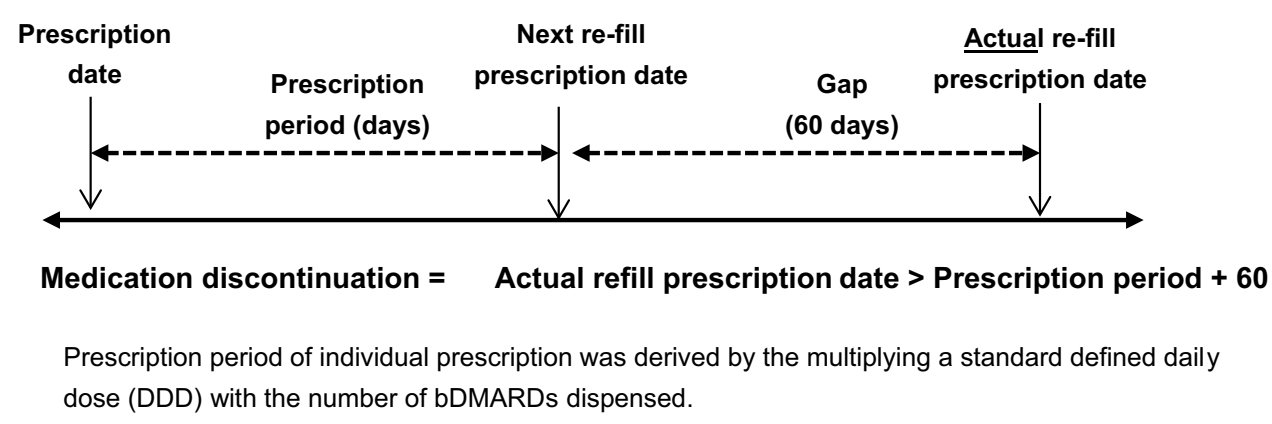

(b) Health care utilization and healthcare cost measurement

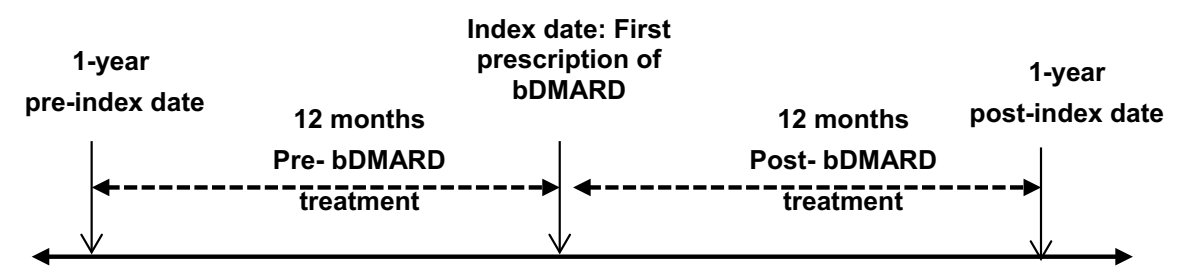




\subsubsection{Resource Utilization}

Patients were allocated into two groups, a persistence and a non-persistence group, over a 12-month period and compared in terms of their resource utilization. Healthcare resource utilization was determined after at least 24 months of follow-up. [12 months before the index date (first initiation of bDMARD and 12 months after index date] (Fig. 1 b). Healthcare resource utilization and associated costs included the following items:

- number of outpatient visits,

- number of all cause-hospitalizations,

- number of re-hospitalizations (re-hospitalization was defined as all-cause hospitalization within 30 days after a hospital discharge),

- length of stay (per hospitalization),

- cost accrued for specific treatments,

- overall cost of treatment.

All costs were converted to US dollars based on the exchange rate on 30 September 2016 (US\$1 = 101.08 Japanese Yen) [30] and adjusted for inflation using the consumer price index [31].

\subsection{Statistical Analysis}

Descriptive statistics were used to analyse demographic characteristics and treatment persistence with bDMARDs. Chi square and Wilcoxon rank sum tests were used to assess the difference between bDMARDs among bDMARD-naïve patients. A Kaplan-Meier analysis was used to calculate the persistence of bDMARD treatment. Differences in persistence were tested for significance using the Log Rank tests. A $p$ value of $\leq 0.05$ was considered statistically significant.

Propensity score matching: To control for potential confounders that could influence treatment initiation with a specific bDMARD, giving rise to selection bias, we employed a 1:1 propensity score-matching method, where patients not selected as a match are dropped from subsequent analyses. Matching attributes were age, gender and the Charlson co-morbidity index (CCI) score [32], using the previously described algorithms by Quan et al. [33].

The propensity score was derived from a logit model as the predicted probability of initiating treatment with a bDMARD given the baseline characteristics with a simple nearest-neighbour matching without replacement, conditional on the common support [34]. To compare the persistence rate of different bDMARDs, pairwise comparisons were performed using the bDMARD with the highest persistence rate as an anchor. Equality and balancing of covariates before and after matching was evaluated by the approach suggested by Rosenbaum and Rubin [35], in which standardized bias before and after matching should be less than 5\% after matching. The analysis was undertaken using STATA (StataCorp LP, College Station, TX, USA).

\section{Results}

\subsection{Study Population}

Based on the inclusion criteria, we identified 6153 bDMARD-naïve patients (Fig. 2).

Table 1 shows the patient characteristics of the bDMARD-naïve persistence and non-persistence groups. The mean age for the total sample was 59 years. The majority of patients were female with an average CCI score of 5 indicating a rather morbid population [20]. In addition, Online supplementary material, Appendix 2 provides an overview of the study population stratified by prescribed bDMARD.

\subsection{Persistence}

Figure 3 presents the Kaplan-Meier curve for the baseline case using a gap definition of 60 days. Overall, the 1-year persistence rate was $85 \%$ (95\% CI 84-86).

For the base case, persistence rates ranged from $82 \%$ for ETN and IFX to $92 \%$ for GOL (Online supplementary material, Appendix 3). Online supplementary material, Appendix 3 also shows Kaplan-Meier curves using alternative gap definitions of 30 and 90 days as the sensitivity analysis. All values are also reported in Table 2 . The results are robust towards the gap definition of 120 days, while a 30-day gap definition led to a stark decrease in persistence rates.

The results using propensity score adjusted survival rates and comparing GOL patients pairwise with GOL, ADL, IFX, CTZ, TCZ and ABT are plotted in Appendix 4.

\subsection{Healthcare Utilization and Cost}

Table 3 outlines the healthcare resource utilization before and after bDMARD treatment initiation stratified by persistence status. The overall sample had about ten outpatient visits at baseline and 16 visits after starting bDMARD treatment. The number of hospital admissions on the other hand declined from 3.3 to 1.6. Additionally, the number of days in hospital decreased from 17 to 12 . The non-persistence group had a significantly higher increase in outpatient visits after bDMARD initiation compared with the persistence group (from 8 to 16 vs. 10 to 16 , respectively) and a significantly lower decrease in hospital admission (from 3.1 to 1.9 vs. 3.5 to 1.4 , respectively).

The associated costs are listed in Table 4. Overall, there was an annual increase in cost from US\$6747 to 


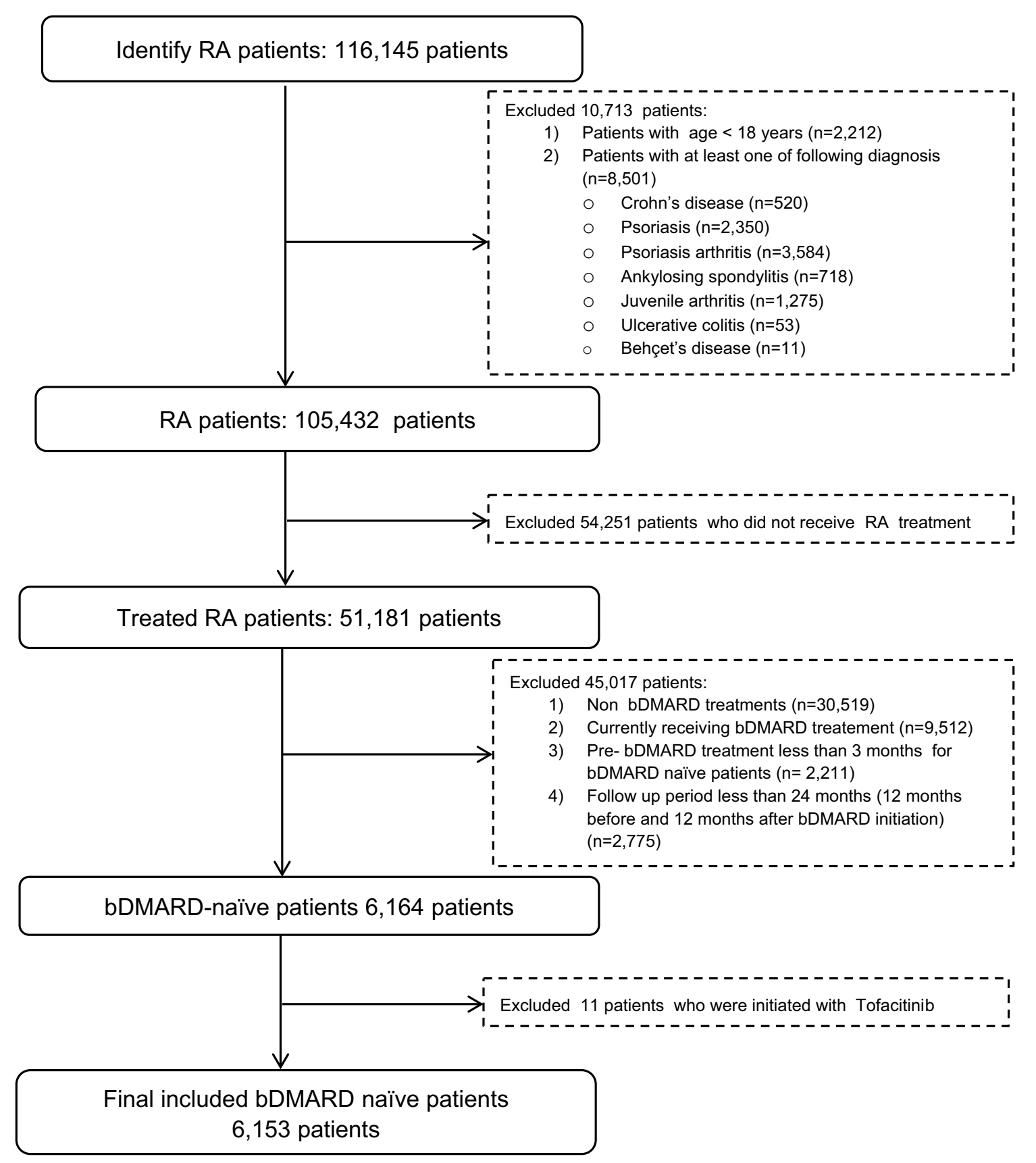

Fig. 2 Patient flow

US $\$ 14,337$ after starting bDMARD treatment. The cost increase was due to RA-related medication costs that increased from US $\$ 3161$ to US $\$ 12,076$. This increase in cost was partially offset by a decrease in hospitalization costs from US\$3072 to US\$1657. The cost increase was lower in the persistence group (US\$7397) than in the non-persistence group (US\$8157). Although RA-related medication costs increased by US\$9106 in the persistence group compared with US\$8629 in the non-persistence group, the reduction in hospitalization cost was greater in the persistence group (US\$-1814 vs. US\$-681). 
Table 1 Patient characteristics of persistence vs. nonpersistence in bDMARD-naïve groups

Fig. 3 Persistence rate of all included patients

\begin{tabular}{|c|c|c|c|c|}
\hline \multirow[t]{2}{*}{ Characteristic, $N(\%)$} & \multicolumn{3}{|c|}{ bDMARD-naïve patients } & \multirow[t]{2}{*}{$P$ value } \\
\hline & Total & Persistence & Non-persistence & \\
\hline RA patients & 6153 & 4867 (79) & $1286(21)$ & \\
\hline Age $($ mean $\pm \mathrm{SD})$ & $59.20 \pm 14.20$ & $59.34 \pm 14.29$ & $58.69 \pm 13.82$ & 0.131 \\
\hline$\leq 60$ years & $2882(47)$ & $2254(46)$ & $628(49)$ & \\
\hline $61-70$ years & $1905(31)$ & $1505(31)$ & $400(31)$ & \\
\hline$>70$ years & $1366(22)$ & $1108(23)$ & $258(20)$ & \\
\hline Gender & & & & 0.198 \\
\hline Male & $1398(23)$ & $1123(23)$ & $275(21)$ & \\
\hline Female & $4755(77)$ & $3744(77)$ & $1011(79)$ & \\
\hline CCI score $($ mean $\pm \mathrm{SD})$ & $5.01 \pm 3.15$ & $5.03 \pm 3.16$ & $4.97 \pm 3.08$ & 0.579 \\
\hline$\leq 2$ & $1341(22)$ & $1064(22)$ & $277(22)$ & \\
\hline $3-5$ & $2663(43)$ & $2094(43)$ & $569(44)$ & \\
\hline$>5$ & $2149(35)$ & 1709 (35) & $440(34)$ & \\
\hline
\end{tabular}

Value present: persistence rate in percent and $95 \%$ confidence intervals by time point bDMARDs biological disease-modifying antirheumatic drugs, $C C I$ Charlson Co-morbidity Index, $C I$ confidence interval, $R A$ rheumatoid arthritis

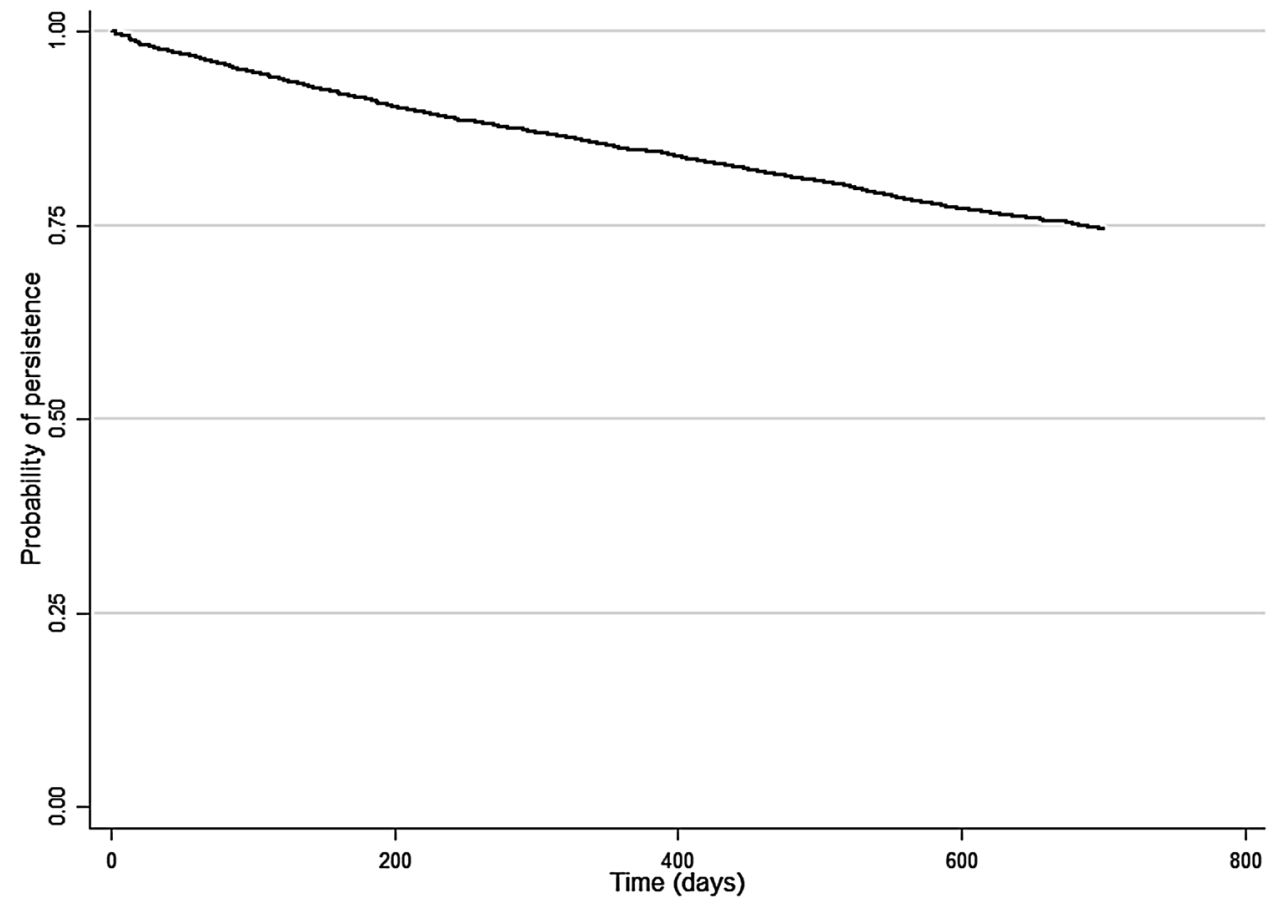

\section{Discussion}

\subsection{Persistence Rates}

Compared to the results from international studies of medication persistence, Japanese bDMARD-naïve patients have a higher persistence rate in the use of bDMARDs for the treatment of RA. The baseline rate of $85 \%$ for bDMARDnaïve patients is at the upper end of that reported in a recent systematic review of 52 studies [6]. The Swedish study by Dalen et al. reported rates of $55-58 \%$. Most other studies from other countries using real-world databases have also reported persistence rates only slightly above $50 \%$ [26].

This is not the first study to report high bDMARDs persistence and adherence in Japanese compared with Western patients across different indications [7]. This phenomenon has been attributed to both cultural beliefs and the authority status attributed to physicians in Japan [36]. Cultural 
Table 2 Unadjusted persistence rates by prescribed bDMARDs

\begin{tabular}{|c|c|c|c|c|c|c|c|c|}
\hline $\begin{array}{l}\text { Time } \\
\text { points } \\
\text { (months) }\end{array}$ & $\begin{array}{l}\text { Total RA } \\
\text { patients }(95 \% \\
\text { CI) }\end{array}$ & $\operatorname{ETN}(95 \% \mathrm{CI})$ & $\operatorname{ADL}(95 \% \mathrm{CI})$ & $\operatorname{IFX}(95 \% \mathrm{CI})$ & GOL $(95 \% \mathrm{CI})$ & CTZ $(95 \% \mathrm{CI})$ & $\mathrm{TCZ}(95 \% \mathrm{CI})$ & $\mathrm{ABT}(95 \% \mathrm{CI})$ \\
\hline \multicolumn{9}{|c|}{ Base-case analysis (gap 60 days) } \\
\hline 6 & $91(90-92)$ & $88(87-90)$ & $93(91-95)$ & $90(89-92)$ & $95(92-96)$ & $97(90-99)$ & $92(90-93)$ & $93(91-95)$ \\
\hline 12 & $85(84-86)$ & $82(80-84)$ & $88(85-90)$ & $82(80-84)$ & $92(89-94)$ & $91(81-96)$ & $86(83-88)$ & $87(83-90)$ \\
\hline 18 & $79(78-80)$ & $76(73-78)$ & $82(79-85)$ & $76(73-78)$ & $88(84-92)$ & $87(75-93)$ & $81(78-84)$ & $79(75-83)$ \\
\hline \multicolumn{9}{|c|}{ Sensitivity analysis (gap 30 days) } \\
\hline 6 & $78(76-78)$ & $70(68-73)$ & $84(81-86)$ & $81(79-83)$ & $87(84-90)$ & $76(65-83)$ & $71(68-74)$ & $81(77-84)$ \\
\hline 12 & $63(62-65)$ & $58(55-60)$ & $74(70-77)$ & $65(62-67)$ & $80(76-84)$ & $42(30-53)$ & $52(48-56)$ & $69(65-73)$ \\
\hline 18 & $51(49-52)$ & $48(45-51)$ & $66(62-70)$ & $48(46-51)$ & $72(66-77)$ & $25(14-38)$ & $39(35-43)$ & $58(53-63)$ \\
\hline \multicolumn{9}{|c|}{ Sensitivity analysis (gap 90 days) } \\
\hline 6 & $95(95-96)$ & $93(91-94)$ & $95(93-96)$ & $96(95-97)$ & $98(96-99)$ & $98(92-99)$ & $95(94-97)$ & $96(93-97)$ \\
\hline 12 & $92(91-92)$ & $88(86-90)$ & $91(89-93)$ & $93(91-94)$ & $96(94-98)$ & $97(87-99)$ & $92(89-94)$ & $92(90-95)$ \\
\hline 18 & $88(87-89)$ & $84(82-86)$ & $86(83-89)$ & $90(84-88)$ & $92(88-95)$ & $90(77-96)$ & $89(86-91)$ & $90(86-92)$ \\
\hline
\end{tabular}

Value present: persistence rate in percent and $95 \%$ confidence intervals by time point

$A B T$ abatacept, $A D L$ adalimumab, $b D M A R D s$ biological disease-modifying antirheumatic drugs, $C I$ confidence interval, $C T Z$ certolizumab pegol, $E T N$ etanercept, $G O L$ golimumab, IFX infliximab, $R A$ rheumatoid arthritis, $T C Z$ tocilizumab

attributes might also explain the high number of observed outpatient visits (9.6 per year in the overall sample), which is a direct consequence of a high persistence that results in a high frequency of monitoring and doctor's visits. This finding confirms OECD data that show Japan and Korea having the highest number of doctors' consultations within the OECD countries, with numbers being twice as high as for some Scandinavian countries [37].

Although we did not explore the reasons for the observed differences in persistence between different bDMARDS, potential explanations might be differences in efficacy and safety profiles [25, 38]. Another factor that is associated with persistence is the administration frequency: Patients using the monthly administration period had better adherence than those using more frequent dosing schedules [39].

A third explanation might be the so-called channelling bias that is defined as an "allocation bias, where drugs with similar therapeutic indications are prescribed to groups of patients with prognostic differences" [40]. During our observation period new bDMARDs have been introduced to the Japanese market and possibly new drugs are prescribed to patients with pre-existing morbidities that would also influence the treatment persistence.

\subsection{Healthcare Utilization and Costs}

The Swedish study reported that persistence was associated with a cost savings of US\$987, while non-persistence led to a cost increase of US\$793 [10]. Of note, the cost of the bDMARDs was not included in this analysis. We found tha, when the cost of medications was included, the increase in cost was actually smaller in the persistence compared with the non-persistence group (US\$7397 vs. US\$8157, respectively). Therefore, persistence was associated with a cost savings of US\$760 per year, which translates into approximately two hospital admissions per year and 6 days in the hospital. While these findings suggest at first glance that persistence with bDMARDs for patients with RA leads to better outcomes in terms of costs and resource utilization, other factors must be taken into consideration. Patients in the nonpersistence groups who discontinue their treatment because of severe side effects, for instance, may subsequently require additional treatments and/or hospitalizations. In such cases, the increase in cost and resource utilization is more directly related to adverse reactions to the bDMARD treatment per se. From a clinical perspective, the choice of bDMARDs should therefore be based not only a high continuation rate but also on a good side-effect profile.

Although we did not include indirect costs in our analysis, it is worth mentioning that the observed avoidance of one hospitalization for the persistent group likely corresponds with a smaller burden for patients and their families and less productivity costs for the total economy as a whole. Previous studies found that productivity costs in Japanese RA patients are indeed significant [41].

\subsection{Limitations}

There are several limitations to this study. Claims data analyses in general can only utilize a very limited set of medical parameters. As a result, we were unable to control for RA-specific disease severity, disease activity and disease duration at the time of bDMARD treatment initiation. We were also unable to determine the reasons for treatment 
Table 3 Healthcare utilization before and after initiation of bDMARD treatment

\begin{tabular}{llll}
\hline Healthcare resource utilization & Overall $(n=6153)$ & Persistence $(n=4867)$ & Non-persistence $(n=1286) \quad P$ value (persistence
\end{tabular} vs. non-persistence)

(1) 12 months prior to bDMARD initiation

Number of OPD visits

\begin{tabular}{|c|c|c|c|c|}
\hline Mean \pm SD & $9.6 \pm 9.2$ & $10.1 \pm 9.6$ & $8.1 \pm 9.7$ & $<0.001$ \\
\hline Median (IQR) & $8(3-13)$ & $8(4-13)$ & $6(2-11)$ & \\
\hline \multicolumn{5}{|c|}{ Number of hospitalizations } \\
\hline Mean \pm SD & $3.3 \pm 3.0$ & $3.5 \pm 2.8$ & $3.1 \pm 2.8$ & \multirow[t]{2}{*}{0.510} \\
\hline Median (IQR) & $3(3-5)$ & $3(3-5)$ & $3(3-5)$ & \\
\hline \multicolumn{5}{|l|}{ Length of stay } \\
\hline Mean \pm SD & $17.2 \pm 39.9$ & $18.4 \pm 21.8$ & $16.9 \pm 23.5$ & \multirow[t]{2}{*}{0.733} \\
\hline Median (IQR) & $8(3-29)$ & $8(4-30)$ & $8(3-27)$ & \\
\hline \multicolumn{5}{|c|}{ Number of re-hospitalizations } \\
\hline Mean $\pm \mathrm{SD}$ & $0.6 \pm 0.4$ & $0.7 \pm 0.8$ & $0.5 \pm 0.8$ & \multirow[t]{2}{*}{0.205} \\
\hline Median (IQR) & $1(1-1)$ & $1(1-1)$ & $1(1-1)$ & \\
\hline \multicolumn{5}{|c|}{ (2) 12 months post-bDMARD treatment initiation } \\
\hline \multicolumn{5}{|c|}{ Number of OPD visits } \\
\hline Mean $\pm \mathrm{SD}$ & $16.4 \pm 13.99$ & $16.4 \pm 13.3$ & $16.3 \pm 13.9$ & \multirow[t]{2}{*}{0.757} \\
\hline Median (IQR) & $13(9-20)$ & $14(9-20)$ & $13(8-18)$ & \\
\hline \multicolumn{5}{|c|}{ Number of hospitalizations } \\
\hline Mean \pm SD & $1.6 \pm 0.7$ & $1.4 \pm 0.7$ & $1.9 \pm 0.6$ & \multirow[t]{2}{*}{0.075} \\
\hline Median (IQR) & $2(1-3)$ & $2(1-3)$ & $2(1-4)$ & \\
\hline \multicolumn{5}{|l|}{ Length of stay } \\
\hline Mean \pm SD & $12.2 \pm 19.1$ & $12.5 \pm 18.7$ & $11.8 \pm 21.0$ & \multirow[t]{2}{*}{0.198} \\
\hline Median (IQR) & $12(8-20)$ & $12(8-20)$ & $12(7-18)$ & \\
\hline \multicolumn{5}{|c|}{ Number of re-hospitalizations } \\
\hline Mean \pm SD & $0.3 \pm 0.1$ & $0.3 \pm 0.6$ & $0.2 \pm 0.4$ & \multirow[t]{2}{*}{0.467} \\
\hline Median (IQR) & $1(0-1)$ & $1(0-1)$ & $1(0-1)$ & \\
\hline
\end{tabular}

Difference in healthcare resources prior to vs. post bDMARD initiation

\begin{tabular}{lrrrr} 
Number of OPD visits & $6.7(0.2),<0.001$ & $6.3(0.2),<0.001$ & $8.2(0.5),<0.001$ & $-1.9(0.6), 0.072$ \\
Number of hospitalizations & $-2.0(0.2),<0.001$ & $-2.1(0.1),<0.001$ & $-1.2(0.2),<0.001$ & $-0.9(0.3), 0.042$ \\
Length of stay & $-5.0(1.1),<0.001$ & $-5.9(1.8),<0.001$ & $-5.1(1.1), 0.001$ & $-0.9(0.9), 0.653$ \\
Number of re-hospitalizations & $-0.3(0.1),<0.001$ & $-0.4(0.2),<0.001$ & $-0.3(0.1),<0.001$ & $-0.1(0.3), 0.411$ \\
\hline
\end{tabular}

bDMARDs biological disease-modifying antirheumatic drugs, $I Q R$ interquartile range, $O P D$ Outpatient Department, $S D$ standard deviation

discontinuation, which could have encompassed adverse events, lack of efficacy or even clinical remission. Also, the persistence rates might be biased downwards if Japanese patients use lower dosages due to weight differences. In that case, the medication supply would be longer for any prescribed drug. This implies that patients who do not refill their prescription might still be under treatment, and our analysis would classify them as being non-persistent. Our inclusion criteria of at least 24 months of coverage in the database might also give rise to a bias if we would have excluded a higher fraction of non-persistent patients relative to persistent patients. In addition, the matching algorithm that was employed to compare persistence rates of different bDMARDs accounts only for age, gender and CCI score. Further research should include other variables that potentially influence persistence rates as well. Examples are concomitant use of MTX that was identified with a better treatment persistence [42].

Regarding medical costs and resource utilization, our analysis is limited to the costs that accrues within the hospital network and do not capture other health service utilization and costs that occur outside this network. Therefore, the estimates in this study provide only a lower bound and true costs might be even higher. However, as we have no reason to believe that either the persistent or the non-persistent group systematically differ in the utilization of external healthcare services, we do not think that this confounds our results.

Last, generalizability of these findings should be approached with caution. Because our data were generated 
Table 4 Healthcare costs before and after initiation of bDMARD treatment

\begin{tabular}{|c|c|c|c|c|c|c|c|}
\hline \multirow{2}{*}{$\begin{array}{l}\text { Healthcare } \\
\text { resources }\end{array}$} & \multicolumn{2}{|l|}{ Overall } & \multicolumn{2}{|l|}{ Persistence } & \multicolumn{2}{|l|}{ Non-persistence } & \multirow{2}{*}{$\begin{array}{l}P \text { value (persis- } \\
\text { tence vs. non- } \\
\text { persistence) }\end{array}$} \\
\hline & 12 months prior & 12 months post & 12 months prior & 12 months post & 12 months prior & 12 months post & \\
\hline \multicolumn{8}{|c|}{ Healthcare cost $($ US\$) $($ mean \pm SD $)$} \\
\hline Total OPD cost & $3675 \pm 1632$ & $12,720 \pm 1704$ & $3664 \pm 1657$ & $12,874 \pm 1691$ & $3702 \pm 1794$ & $12,540 \pm 1765$ & $0.063 / 0.960$ \\
\hline Laboratory cost & $55 \pm 16$ & $54 \pm 18$ & $58 \pm 17$ & $52 \pm 18$ & $35 \pm 406$ & $60 \pm 21$ & $<0.001 / 0.233$ \\
\hline Radiology cost & $49 \pm 16$ & $38 \pm 15$ & $47 \pm 16$ & $34 \pm 14$ & $55 \pm 17$ & $40 \pm 19$ & $0.027 /<0.001$ \\
\hline $\begin{array}{l}\text { Management } \\
\text { cost (drug, } \\
\text { counselling } \\
\text { and general } \\
\text { management) }\end{array}$ & $151 \pm 140$ & $465 \pm 244$ & $156 \pm 129$ & $458 \pm 238$ & $130 \pm 184$ & $497 \pm 264$ & $0.011 / 0.036$ \\
\hline $\begin{array}{l}\text { RA-related } \\
\text { medication } \\
\text { cost }\end{array}$ & $3161 \pm 1257$ & $12,076 \pm 6258$ & $3147 \pm 1371$ & $12,253 \pm 6285$ & $3215 \pm 1,2,68$ & $11,844 \pm 6123$ & $0.041 /<0.001$ \\
\hline $\begin{array}{l}\text { Non-RA-related } \\
\text { medication } \\
\text { cost }\end{array}$ & $225 \pm 341$ & $51 \pm 577$ & $277 \pm 368$ & $42 \pm 447$ & $215 \pm 166$ & $57 \pm 975$ & $0.393 / 0.019$ \\
\hline $\begin{array}{l}\text { Surgery and } \\
\text { other proce- } \\
\text { dure cost }\end{array}$ & $29 \pm 519$ & $29 \pm 465$ & $25 \pm 501$ & $29 \pm 474$ & $47 \pm 598$ & $38 \pm 420$ & $0.921 / 0.703$ \\
\hline Other cost & $4 \pm 47$ & $6 \pm 61$ & $3 \pm 49$ & $6 \pm 65$ & $5 \pm 38$ & $5 \pm 38$ & $0.849 / 0.474$ \\
\hline $\begin{array}{l}\text { Total hospitali- } \\
\text { zation cost }\end{array}$ & $3072 \pm 5194$ & $1657 \pm 4723$ & $3283 \pm 5024$ & $1469 \pm 4669$ & $2950 \pm 5925$ & $2269 \pm 4947$ & $0.513 / 0.008$ \\
\hline $\begin{array}{l}\text { Total healthcare } \\
\text { cost }\end{array}$ & $6747 \pm 5491$ & $14,337 \pm 11,001$ & $6946 \pm 5430$ & $14,343 \pm 5008$ & $6652 \pm 6280$ & $14,809 \pm 5440$ & $0.793 / 0.412$ \\
\hline \multicolumn{8}{|c|}{ Difference in healthcare costs prior to vs. post biological initiation (US\$) [mean (SE, $p$ value)] } \\
\hline Total OPD cost & \multicolumn{2}{|c|}{$9026(6689),<0.001$} & \multicolumn{2}{|c|}{$9210(6242),<0.001$} & \multicolumn{2}{|c|}{$8838(6271),<0.001$} & $372(578), 0.010$ \\
\hline Laboratory cost & \multicolumn{2}{|l|}{$-1(17), 0.710$} & \multicolumn{2}{|l|}{$-7(13), 0.07$} & \multicolumn{2}{|l|}{$25(17),<0.001$} & $-32(68), 0.011$ \\
\hline Radiology cost & \multicolumn{2}{|l|}{$-11(11), 0.001$} & \multicolumn{2}{|l|}{$-13(22),<0.001$} & \multicolumn{2}{|l|}{$-15(32), 0.830$} & $2(6), 0.766$ \\
\hline $\begin{array}{l}\text { Management } \\
\text { cost (drug, } \\
\text { counselling } \\
\text { and general } \\
\text { management) }\end{array}$ & \multicolumn{2}{|c|}{$314(125),<0.001$} & \multicolumn{2}{|c|}{$303(270),<0.001$} & \multicolumn{2}{|c|}{$367(288),<0.001$} & $-65(44), 0.021$ \\
\hline $\begin{array}{l}\text { RA-related } \\
\text { medication } \\
\text { cost }\end{array}$ & \multicolumn{2}{|c|}{8915 (4834), 0.006} & \multicolumn{2}{|c|}{$9106(7582),<0.001$} & \multicolumn{2}{|c|}{$8629(6343),<0.001$} & 477 (148), 0.032 \\
\hline $\begin{array}{l}\text { Non-RA-related } \\
\text { medication } \\
\text { cost }\end{array}$ & \multicolumn{2}{|c|}{$-174(226),<0.001$} & \multicolumn{2}{|l|}{-185 (39), 0.124} & \multicolumn{2}{|l|}{$-158(33), 0.018$} & $-27(11), 0.002$ \\
\hline $\begin{array}{l}\text { Surgery and } \\
\text { other proce- } \\
\text { dure cost }\end{array}$ & \multicolumn{2}{|l|}{$0(8), 0.962$} & \multicolumn{2}{|l|}{$4(1), 0.703$} & \multicolumn{2}{|l|}{$-10(5), 0.451$} & $14(11), 0.416$ \\
\hline Other cost & \multicolumn{2}{|l|}{$2(8), 0.153$} & \multicolumn{2}{|l|}{$3(0.9), 0.037$} & \multicolumn{2}{|l|}{0 (174), 0.953} & $3(2), 0.342$ \\
\hline $\begin{array}{l}\text { Total hospitali- } \\
\text { zation costs }\end{array}$ & \multicolumn{2}{|c|}{$-1416(1020),<0.001$} & \multicolumn{2}{|c|}{$-1814(1137),<0.001$} & $-681(516), 0.00$ & & $\begin{array}{l}-1132(721) \\
0.021\end{array}$ \\
\hline $\begin{array}{l}\text { Total healthcare } \\
\text { costs }\end{array}$ & 7630 (5057), 0.0 & & 7397 (4549), 0.4 & & 8157 (6101), 0.0 & & $\begin{array}{c}-760(277) \\
0.034\end{array}$ \\
\hline
\end{tabular}

DDMARDs biological disease-modifying antirheumatic drugs, $O P D$ Outpatient Department, $R A$ rheumatoid arthritis, $S D$ standard deviation

from large Japanese DPC hospitals, we cannot rule out the existence of a bias towards patients whose RA was more severe than that of the general patient population. The rather high CCI score in our sample supports this possibility. The 
results may therefore not be representative of the daily practice of RA treatment in Japan.

\section{Conclusion}

Based on an administrative claims data set from large Japanese hospitals we found that Japanese patients with RA who had poor persistence with biological agents do cause higher costs to the healthcare system compared to patients who are persistent with their medications. The higher observed costs are mainly due to differences in the number of hospitalizations. Acknowledging several limitations of database studies, further studies are warranted to validate our findings in a clinical setting. Despite its limitations, this analysis highlights the relevance of defining drug persistence as a treatment goal in RA.

Acknowledgements We thank Margueritte Mabry White M.D. and Negar Jamshidi for editing and proofreading the manuscript.

Authors contributions JM and RS made substantial contributions to the conception and design, the acquisition of data, and the analysis and interpretation of data. JM drafted the manuscript. JM, HK and RS discussed the critical important intellectual content and revised the manuscript accordingly.

\section{Compliance with Ethical Standards}

Funding statement This work was supported by Janssen Pharmaceutical KK, the company that approved and funded the study. The funders had no role in study design, data collection and analysis, decision to publish, or preparation of the manuscript.

Conflict of interest JM and RS are affiliated with Janssen Pharmaceutical KK, a company that markets drugs for the treatment of RA. HK received research grants from Abbvie GK, Astellas Pharma, AstraZeneca K.K., Bristol- Myers K.K., Chugai Pharmaceutical Co, Ltd., Eisai Co. Ltd., Mitsubishi Tanabe Pharma Co., Novartis Pharma K.K., Takeda Pharmaceutical Co. Ltd.; speaking fees from AbbVie GK, Astellas Pharma, Ayumi Pharamaceutical Corporation, Bristol- Myers K.K., Chugai Pharmaceutical Co. Ltd., Eisai Co. Ltd., Janssen Pharmaceutical K.K., Mitsubishi Tanabe Pharma Co., Novartis Pharma K.K., and Takeda Pharmaceutical Co. Ltd.; consultant fees from Abbvie GK, Eli Lilly Japan K.K., Novartis Pharma K.K., Nippon Kayaku Co. Ltd, Pfizer Japan Inc, UCB Pharma, Santen Pharmaceutical Co Ltd. and Sanofi K.K.

Availability of data and materials We used the MDV database, which is a third-party database commercially available from Medical Data Vision Co., Ltd., Tokyo Japan: https://www.mdv.co.jp/company/outli ne/, TEL: + 81-3-5283-6911, FAX: + 81-3-5283-6811, e-mail: ebm_ sales@mdv.co.jp. Accessing the data involves a fee.

Ethics statement In the MDV database, the claim records of each patient are anonymously linked using de-identified codes, making it impossible to identify them.
Open Access This article is distributed under the terms of the Creative Commons Attribution-NonCommercial 4.0 International License (http://creativecommons.org/licenses/by-nc/4.0/), which permits any noncommercial use, distribution, and reproduction in any medium, provided you give appropriate credit to the original author(s) and the source, provide a link to the Creative Commons license, and indicate if changes were made.

\section{References}

1. Yamanaka H, Sugiyama N, Inoue E, Taniguchi A, Momohara S. Estimates of the prevalence of and current treatment practices for rheumatoid arthritis in Japan using reimbursement data from health insurance societies and the IORRA cohort (I). Mod Rheumatol. 2014;24:33-40.

2. Smolen JS, Landewé R, Breedveld FC, Dougados M, Emery P, et al. EULAR recommendations for the management of rheumatoid arthritis with synthetic and biological disease-modifying antirheumatic drugs. Ann Rheum Dis. 2010;69:964-75.

3. Curtis J, Singh J. The Use of biologics in rheumatoid arthritis: current and emerging paradigms of care. Clin Ther. 2001;33:679-707.

4. Listing J, Kekow J, Manger B, Burmester G-R, Pattloch D, et al. Mortality in rheumatoid arthritis: the impact of disease activity, treatment with glucocorticoids, TNF $\alpha$ inhibitors and rituximab. Ann Rheum Dis. 2015;74:415-21.

5. Cramer JA, Roy A, Burrell A, Fairchild CJ, Fuldeore MJ, et al. Medication compliance and persistence: terminology and definitions. Value Health. 2008;11:44-7.

6. Blum MA, Koo D, Doshi JA. Measurement and rates of persistence with and adherence to biologics for rheumatoid arthritis: a systematic review. Clin Ther. 2011;33:901-13.

7. Mahlich J, Sruamsiri R. Persistence with biologic agents for the treatment of rheumatoid arthritis in Japan. Patient Preference Adherence. 2016;10:1509-19.

8. Sakai R, Tanaka M, Nanki T, Watanabe K, Yamazaki H, et al. Drug retention rates and relevant risk factors for drug discontinuation due to adverse events in rheumatoid arthritis patients receiving anticytokine therapy with different target molecules. Ann Rheum Dis. 2012;71:1820-6.

9. Hishitani Y, Ogata A, Shima Y, et al. Retention of tocilizumab and anti-tumour necrosis factor drugs in the treatment of rheumatoid arthritis. Scand J Rheumatol. 2013;42:253-9.

10. Dalén J, Svedbom A, Black C, Lyu R, Ding Q, et al. Treatment persistence among patients with immune-mediated rheumatic disease newly treated with subcutaneous TNF-alpha inhibitors and costs associated with non-persistence. Rheumatol Int. 2016;36:987-95.

11. Tang B, Rahman M, Waters HC, Callegari P. Treatment persistence with adalimumab, etanercept, or infliximab in combination with methotrexate and the effects on health care costs in patients with rheumatoid arthritis. Clin Ther. 2008;30:1375-84.

12. Meissner B, Trivedi D, You M, Rosenblatt L. Switching of biologic disease modifying anti-rheumatic drugs in patients with rheumatoid arthritis in a real world setting. J Med Econ. 2014;17:259-65.

13. Saokaew S, Sugimoto T, Kamae I, Pratoomsoot C, Chaiyakunapruk N. Healthcare databases in Thailand and Japan: potential sources for health technology assessment research. PLoS One. 2015; 10:e0141993. 
14. Wang K, Li P, Chen L, Kato K, Kobayashi M, et al. Impact of the Japanese diagnosis procedure combination-based payment system in Japan. J Med Syst. 2010;34:95-100.

15. Cheung S, Hamuro Y, Mahlich J, Nakahara T, Sruamsiri R, Tsukazawa S. Drug utilization of Japanese patients diagnosed with schizophrenia: an administrative database analysis. Clin Drug Investig. 2017;37(6):559-69.

16. Sruamsiri R, Ferchichi S, Jamotte A, Toumi M, Kubo H, Mahlich J. Impact of patient characteristics and treatment procedures on hospitalisation cost and length of stay in Japanese patients with influenza: a structural equation modelling approach. Influenza Other Respir Viruses. 2017;11(6):543-55.

17. Sruamsiri R, Kubo H, Mahlich J. Hospitalization costs and length of stay of Japanese children with respiratory syncytial virus: a structural equation modeling approach. Medicine. 2018;97(29):e11491.

18. Guelfucci F, Kaneko Y, Mahlich J, Sruamsiri R. Cost of depression in Japanese patients with rheumatoid arthritis: evidence from administrative data. Rheumatol Therapy. 2018;5(1):171-83.

19. Mahlich J, Sruamsiri R. Treatment patterns of rheumatoid arthritis in Japanese hospitals and predictors of the initiation of biologic agents. Curr Med Res Opin. 2017;33(1):101-7.

20. Teramoto T, Uno K, Miyoshi I, Khan I, Gorcyca K, Sanchez R, Yoshida S, Mawatari K, Masaki T, Arai H, Yamashita S. Lowdensity lipoprotein cholesterol levels and lipid-modifying therapy prescription patterns in the real world: An analysis of more than 33,000 high cardiovascular risk patients in Japan. Atherosclerosis. 2016;251:248-54.

21. Chang C, Sakaguchi M, Dolin P. Epidemiology of lactic acidosis in type 2 diabetes patients with metformin in Japan. Pharmacoepidemiol Drug Saf. 2016;25(10):1196-203.

22. Mahlich J, Tsubota A, Imanaka K, Enjo K. Burden of illness of chemotherapy in castration-resistant prostate cancer patients in Japan: a retrospective database analysis. Curr Med Res Opin. 2018. https://doi.org/10.1080/03007995.2018.1462782.

23. Cheung S, Hamuro Y, Mahlich J, Nakayama M, Tsubota A. Treatment pathways of Japanese prostate cancer patients-a retrospective transition analysis with administrative data. PLoS One. 2018;13(4):e0195789.

24. Neubauer S, Cifaldi M, Mittendorf T, Ganguli A, Wolff M, Zeidler J. Biologic TNF inhibiting agents for treatment of rheumatoid arthritis: persistence and dosing patterns in Germany. Health Econ Rev. 2014;4(1):32.

25. Svedbom A, Storck C, Kachroo S, Govoni M, Khalifa A. Persistence with golimumab in immune-mediated rheumatic diseases: a systematic review of real-world evidence in rheumatoid arthritis, axial spondyloarthritis, and psoriatic arthritis. Patient Preference Adherence. 2017;11:719-29.

26. Wu E, Chen L, Birnbaum H, Yang E, Cifaldi M. Retrospective claims data analysis of dosage adjustment patterns of TNF antagonists among patients with rheumatoid arthritis. Curr Med Res Opin. 2008;24:2229-40.
27. Yeaw J, Benner JS, Walt JG, Sian S, Smith DB. Comparing adherence and persistence across 6 chronic medication classes. J Manag Care Pharm. 2009; 15:728-40.

28. Sruamsiri R, Iwasaki K, Tang W, Mahlich J. Persistence rates and medical costs of biological therapies for psoriasis treatment in Japan: a real-world data study using a claims database. BMC Dermatol. 2018;18:5.

29. Singh JA, Saag KG, Bridges SL Jr, Akl EA, Bannuru RR, et al. 2015 American College of Rheumatology Guideline for the treatment of Rheumatoid Arthritis. Arthritis Rheumatol. 2016;68:1-26.

30. Bank of Japan. Exchange rates. 2016. https://www.boj.or.jp/en/ statistics/market/forex/fxdaily/index.htm/. Accessed 25 July 2017.

31. Statistics of Japan. Consumer price index. 2016. https://www.estat.go.jp/en. Accessed 25 July 2017.

32. Charlson ME, Pompei P, Ales KL, MacKenzie CR. A new method of classifying prognostic comorbidity in longitudinal studies: development and validation. J Chronic Dis. 1987;40:373-83.

33. Quan H, Sundararajan V, Halfon P, Fong A, Burnand B, et al. Coding algorithms for defining comorbidities in ICD-9-CM and ICD-10 administrative data. Med Care. 2005;43:1130-9.

34. Abadie A, Drukker D, Herr J, Imbens G. Implementing matching estimators for average treatment effects in Stata. Stata J. 2004;4:290-311.

35. Rosenbaum P, Rubin D. The central role of the propensity score in observational studies for causalc effects. Biometrika. 1983;70:41-55.

36. Chia LR, Schlenk EA, Dunbar-Jacob J. Effect of personal and cultural beliefs on medication adherence in the elderly. Drugs Aging. 2006;23:191-202.

37. OECD (2018) Doctors' consultations (indicator). https://doi. org/10.1787/173dcf26-en. Accessed 26 July 2018.

38. Keystone EC, Genovese MC, Hall S, et al. Safety and efficacy of subcutaneous golimumab in patients with active rheumatoid arthritis despite methotrexate therapy: final 5-year results of the GO-FORWARD trial. J Rheumatol. 2016;43(2):298-306.

39. Calvo-Alen J, Monteagudo I, Salvador G, et al. Non-adherence to subcutaneous biological medication in patients with rheumatoid arthritis: a multicentre, non-interventional study. Clin Exp Rheumatol. 2017;35(3):423-30.

40. Petri $\mathrm{H}$, Urquhart J. Channeling bias in the interpretation of drug effects. Stat Med. 1991;10(4):577-81.

41. Sruamsiri R, Mahlich J, Tanaka E, Yamanaka H. Productivity loss of Japanese patients with rheumatoid arthritis-a cross-sectional survey. Mod Rheumatol. 2018;28(3):482-9.

42. Kristensen LE, Saxne T, Nilsson J, Geborek P. Impact of concomitant DMARD therapy on adherence to treatment with etanercept and infliximab in rheumatoid arthritis. Results from a six-year observational study in southern Sweden. Arthritis Res Therapy. 2006;8:R174. 